\title{
The simulation of design electric vehicle charging circuit
}

\author{
Linming Wang ${ }^{1,}$, Xiaorui $\mathrm{Wu}^{2, \mathrm{~b}}$ \\ ${ }^{1}$ Zhengzhou institute of industrial Technology Applications, China \\ ${ }^{2}$ Zhengzhou institute of industrial Technology Applications,China \\ a904830352@qq.com, bfengzhimeng1989@126.com
}

Keywords:single chip microcomputer, charger,A / D conversion,C language.

\begin{abstract}
This design uses AT89C51 microcontroller as the control core,to control charger into diff erent stages .The charging circuit is mainly composed of rectifier bridge type circuit,singlephase hal f bridge inverter circuit and highfrequency rectifier circuit composition ,to control circuit are mainly used for realtime detection and simulation of theelectric car charger all sorts of input signal.Softwar e part using $C$ language to write program.SCM according to the different charging status of the batt ery to take differentcharging methods,through A / D conversion,the output feedback voltageto pow er the real-time monitoring and control .
\end{abstract}

\section{Introduction}

The emergence of electric cars to the progress of human society and made tremendous cintributions the environmental ection work.But current electric car chargers existences many problems. Among them, the electric car charger with electric power cannot be automatically outage is particularly prominent. A series of problems are forcing enterprises to actively improve the electric bike charger technology, to improve the quality of the charger.

This design for electric vehicle charging problem such as slow, safe enough not, by single chip microcomputer as main control chip.Design can realize fast charge, and can be filled with the electric car charger automatically outages after power analog circuits.

\section{The overall scheme design}

\section{The project design}

This design on the basis of lead battery quick charging theory, adopt the half bridge converter high frequency switch regulated power supply on battery charging. And through the single chip microcomputer to control the charging process.

\section{The control mode}

This electric car charger analog circuit design make full use of the single chip microcomputer rich $\mathrm{I} / \mathrm{O}$ port and reliable control, through to the voltage of the battery and A/D conversion will signal send to the microcontroller. And MCU internal program deal with it and then output the corresponding signal, in order to lead in the process of charging battery testing and make corresponding control processing. The overall control scheme is shown in figure 1

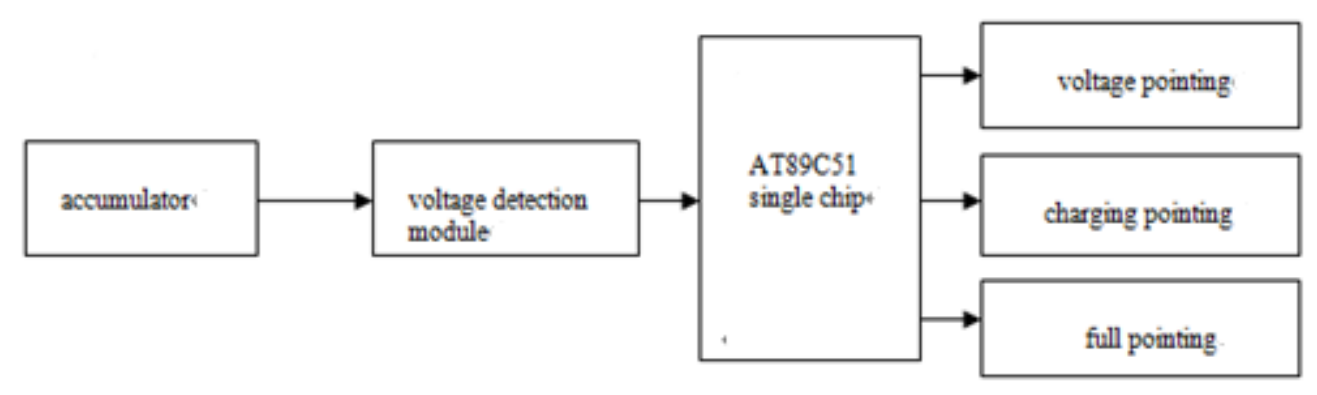

Figure 1 single chip microcomputer control scheme as a whole 


\section{Work flow chart}

The electric vehicle charging circuit simulation design based on single chip processor as the core, using voltage detection module to test the terminal voltage of battery, through $A / D$ conversion module for single chip microcomputer. Microcontroller based on the current voltage value judgment charging status. When the battery is full, it will automatically stop charging. The work flow chart is shown in figure 2.

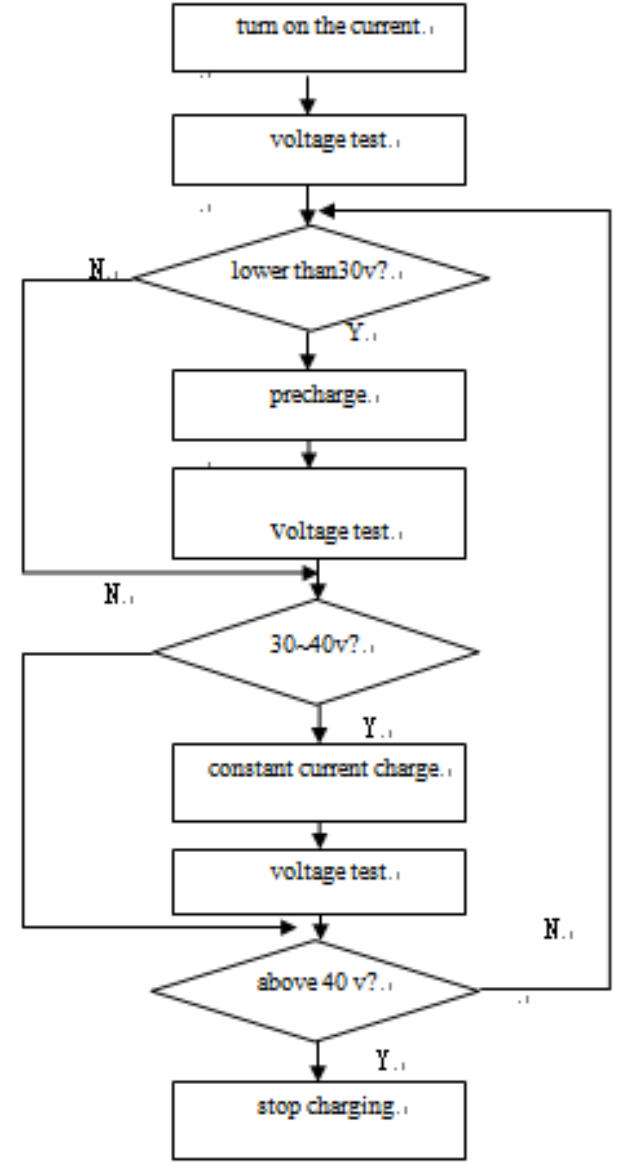

Figure 2 work flow chart

\section{The simulation system}

When the battery capacity is less than $30 \mathrm{v}$, the yellow LED lights flashing. It is recharge preliminary stage, red LED lights flashing at the same time, dissatisfaction with the battery,that electric car charger is battery charging.as shown in figure 4 (a).

When the battery power between 30 to $40 \mathrm{v}$, blue LED lights flashing,is the constant current charging stage. Red LED lights flashing at the same time, dissatisfaction with the battery, electric car charger is charging. As shown in figure 4 (b).

When the battery power arrive at higher than $40 \mathrm{v}$, green LED lights flashing,the battery is full, red LED lights go out at the same time.The battery has been from discontent to state.At the same time electric car charger without electricity, stop working. As shown in figure 4 (c).

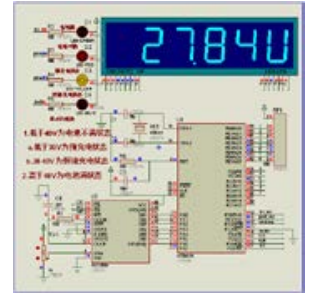

(a)

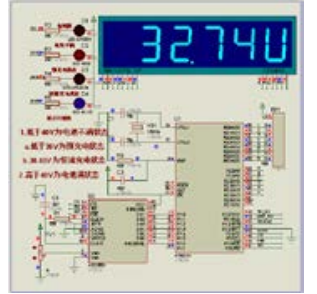

(b)

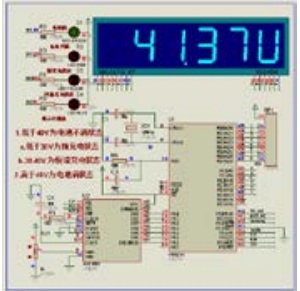

(c)

Figure 3 system simulation results 


\section{Discussion and conclusion}

Electric vehicle battery is the core of electric vehicle battery life and performance stability, So the stand or fall of its performance determines the overall quality of the electric car. Electric car chargers, directly affects the efficiency and service life of the battery.

This design uses the single chip microcomputer as main control chip, reliable microcontroller control ability, the rich I/O port, and the advantages of low voltage, low power consumption.This design can realize fast charge, and can automatically power electric car charger analog circuits,to make the process become more secure.So, the material can be widely applied.

\section{Reference}

[1]Jian Zhao. Electric vehicle battery remaining power forecast method research[D]. Dalian university of technology,2006.

[2]Chun-fang wang. Electric bicycle fast charger research[J]. New technology of electrical power,2012(01),93-96.

[3] Chao-qing Li. Single chip microcomputer principle and interface technology[M]. Beijing aerospace education publishing house, 2007.

[4]Wei-bing Li. Electric smart charger design[J]. Manufacturing automation, 2012(01),138-141.

[5]Bo Zhao. The electric car research of quick charger[D]. Southwest petroleum university, 2012.

[6]Guang-ming Zhao. Battery quick charging method research[J]. Communication power technology, 2012(04),128-130. 